\title{
Definiteness in the Zarma determiner phrase
}

\author{
Waheed Ayisa Jayeola \\ Lecturer \\ Department of Linguistics and African Languages \\ Obafemi Awolowo University, Ile-Ife, Nigeria \\ E-mail: jayeolawaheed@yahoo.com
}

Submitted: March 29, 2018/ Accepted: September 18, 2019/ Published: December 30, 2019

\begin{abstract}
Adjectives in definite Determiner Phrases of Zarma, a Nilo-Saharan language trigger an additional (suffixed/base-merged) lexical determiner; in the event of adjectives modifying nouns, definite determiners can occur with either the nouns or the adjectives or both. In all of these cases, no different readings obtain. Structured interviews were conducted with Zarma native speakers to collect the data for this study. I analyse the phenomenon as a case of definite determiner doubling which does not bear on any form of agreement relations. I further suggest that definite determiner and its subsets - numeral, demonstrative, and quantifier do not overlap. However, each of these can occur alongside adjectives within the DP. Consequently, I consider the adjective as an exponent of the adjunct category. Based on Abney's DP-Hypothesis and the restrictive theory of the Minimalist Program, the paper argues that the asymmetry in the surface realizations of elements/constituents within the Zarma DP is the effect of movement.
\end{abstract}

Keywords: definite determiner, adjective, functional head, determiner doubling, constituent order

\section{Introduction}

Cross linguistically, variations exist in the way definite expressions are shown. Thus, it is possible to find languages where definite descriptions are realized through the combination of two words: a lexical word, mostly of the category $\mathrm{N}$ (Noun), and a functional word of the category D (Determiner), which provides reference to an individual marked as specific or known. It is possible to find in some languages what has been described in the literature as definite adjective; it seems like a vestige of this phenomenon exists in Zarma but it is not treated as such. It is also possible to find languages with a single word capable of dual interpretations either as a definite description or as an indefinite expression. It is interesting to 
mention that the two possibilities are available to Zarma, a Songhai language of the Nilo-Saharan family spoken in some north western states of Nigeria and places in the Republics of Niger, Benin and Mali. A small number of nouns in Zarma are taken to be composites of two words (lexical and functional) whereas in a large number of its nominal expressions the particle that functions as the exponent of definiteness or referentiality is simply missing. However, it would be argued that such definite expressions contain a covert category that does not affect the forms of the words in which it is realized. Thus, definite expressions devoid of an overt definite marker are assumed to have phonetic forms with descriptive denotations as well as a null category with a referential value. This is done with a view to explaining the idiosyncrasy of Zarma in relation to its mapping of syntactic structures to Logical Form (LF) i.e. the interpretive interface.

Thus, the purpose of the present article is to investigate the patterns of the distribution of definite determiner in relation to nouns and adjectives within the DPs of Zarma. And I shall put up the claim that the occurrence of the items recognised as the definite determiner marker either with nouns or adjectives is not an instance of agreement marking but a case of determiner doubling. Also, it shall be shown that the definite determiner is in complementary distribution with its subsets - numeral, demonstrative and quantifier. This shall be undertaken within the confines of the DP analysis (Abney, 1987; Longobardi, 1994, among others) where the determiner is treated as a functional category which necessarily projects its own phrase and takes a noun phrase (NP) as its complement. Relevant to this study are works on Arabic by Fassi Fehri (1999) and Gungbe by Aboh (2004a, 2013), where adjective and determiner (Specificity and Number) respectively occur after the head noun in their superficial syntax. The phonetic forms of the resultant structures are considered to have been so derived by assuming Kayne's (1994) Antisymmetry Theory, where all movement is to the left and no headedness parameter is assumed.

The paper proceeds as follows: the first section discusses the rudiments of the theoretical framework employed for this study. In the second section, I present empirical evidence for the presence of definite and indefinite articles which may not be realized overtly. I discuss noun-attributive modifiers in the third section. Here, I argue that relative clauses and adjectives are traditional modifiers of nouns but more emphasis is placed on the behaviours of adjectives in terms of their relationships with nouns within the DPs. The character of adjectives in relation to their interaction with some functional categories which prevent co-occurrence makes the proposal for double definiteness and the treatment of adjectives as an adjunct category worthwhile. The last section concludes the discussion. 


\section{Theoretical Framework}

This study is undertaken within the tenets of the Minimalist Program, Chomsky $(1993,1995)$ and several other versions including the DP-hypothesis which is one of the major hypotheses that have been incorporated into the program. The minimalist program, based on compatibility, is strongly aided by Kayne's (1994) Antisymmetry Theory. The Minimalist Program (MP) is considered as an attempt to reduce the levels of linguistic representations to two so that superfluous steps in the analysis of linguistic constructs can be easily eliminated. Thus, the two levels of linguistic representations that are postulated in the MP referred to as interfaces are the Phonetic Form (PF) and the Logical Form (LF). Similarly, the restrictive theory of the Minimalist Program incorporates a movement approach and focuses on the order of phrase structure composition by "operation merge". On its part, the DP hypothesis recognizes determiner (D) rather than the head noun, as the head of its own phrase (DP) (Abney, 1987). The empirical and theoretical argument provided by Abney is that, Determiner Phrase, a functional category, is the maximal category that is projected by the class of determiner elements and which heads the noun phrase or has the noun phrase as its complement. The kind of complex constituent orders found in Zarma seems to be the focus of Kayne's (1994) Antisymmetry Theory, which through the Linear Correspondence Axiom (LCA) seeks to place restriction on the possible syntactic representations that are available to human language. This approach favours the position that only one linear order is available for all languages which is Spec-Head-Complement. According to Kayne, languages that deviate from the order are assumed to involve/employ movement at one stage in the development of such languages.

\section{Zarma Definite/Indefinite Article}

Generally speaking, article is a term used in the grammatical classification of words, which refer to a subclass of determiners whose primary role is to differentiate the uses of nouns. According to Matthewson (1998, p. 25) articles do not have a unique semantic value across languages, thus, a distinction is usually made into definite and indefinite (or non-definite) types. It is a category that expresses the referential properties of nouns. In Zarma, article (definite/indefinite) appears consistently after the nouns.

Definite article, from cross linguistic perspective, expresses definiteness. Thus, the association of a definite determiner to a noun in Zarma suggests that either the interlocutors share the referent of the noun in question or that the definite determiner limits the interpretation of the noun. Morphologically, the marking of 
definiteness on nouns is not straightforward as it is possible to realize the item as a separate word or an inflected suffix or enclitic on the noun stem which within the spectrum of the minimalist program is understood as the output of operation merge. Consider in this connection the following illustrations in (1).

\begin{tabular}{|c|c|c|c|}
\hline \multirow[t]{2}{*}{$1 \mathrm{a}}$. & àlmárí & - & evening \\
\hline & àlmáró & - & the evening \\
\hline \multirow[t]{2}{*}{ b. } & hárí & - & water \\
\hline & ii háró & - & the water \\
\hline \multirow[t]{2}{*}{ c. } & má & - & name \\
\hline & máá & - & the name \\
\hline \multirow[t]{2}{*}{ d. } & sáná & - & needle \\
\hline & sáná á & - & the needle \\
\hline \multirow[t]{2}{*}{ e. } & kùsú & - & water pot \\
\hline & ii kùsó & - & the water pot \\
\hline \multirow[t]{2}{*}{ f. } & bónkòní & - & king \\
\hline & bónkònó & - & the king \\
\hline
\end{tabular}

From the data in (1), definite determiner markers are essentially post nominal. They cause a change in the form of the vowels and the form or shape of the vowel seems to bear largely on some phonological accounts like agreement or vowel harmony. The English glosses provided for the data in (1) suggest that the definite determiner is singular, and could be marked by either $o$ or $a$. The reason for this is that number in Zarma is a functional category that independently projects into a Number Phrase and is highly restricted in terms of co-occurring with definite article and other functional categories (see Jayeola, 2016). The realisation of the definite article marker as either an inflectional affix (enclitic) or a free standing morpheme may be sensitive to speech rate which could be spontaneous or slow. Baring other phonological/morphological facts, in normal or spontaneous speech, the definite article is often realised as a free standing morpheme as shown in (2).

2a. má ó bèrì
name Def big
'the big name'
b. hábú ó rá
market Def $\mathrm{P}$
'in the market'


A glance at the examples in $(1 \& 2)$ shows that the marking of definiteness on nouns alternates between the use of $\mathbf{0}$ and a. Tentatively, it is speculated that the alternation between the choice of $\mathbf{o} / \mathbf{a}$ as the definite article marker could be explained in terms of assimilation or distribution.

It is conceivable from the data in (1) and (2) that definite determiner markers are essentially post nominal. However, it is harder to capture in clear terms the distribution of [o] and [a] which are the concrete markers of the definite determiner because they could be realised as either an inflectional affix (enclitic) to demonstrate the effect of merge or as a free standing morpheme. The situation is made difficult by the irregularity observed in the speech rate effect which could be spontaneous or slow. It is common to realise the marker as a free standing morpheme in a slow speech but it does not mean that we cannot find it as an enclitic. This is the case as illustrated in (3).

\begin{tabular}{|c|c|c|c|}
\hline $3 \mathrm{a}$. & má-ó & bèrì & \\
\hline & name-Def & big & \\
\hline & 'the big name' & & \\
\hline b. & hábú-ó & rá & \\
\hline & $\begin{array}{l}\text { market-Def } \\
\text { 'in the market' }\end{array}$ & $\mathrm{P}$ & \\
\hline $\mathrm{i}$ & kùsó & bèrì & \\
\hline & water pot-Def & big & \\
\hline & 'the big water pot & & \\
\hline ii & kùsú & ó & bèrì \\
\hline & water pot & Def & big \\
\hline & 'the big water pot & & \\
\hline $\mathrm{i}$ & chíní & ó & rá \\
\hline & night & Def & $\mathrm{P}$ \\
\hline & 'in the night' & & \\
\hline ii & chínó & rá & \\
\hline & $\begin{array}{l}\text { night-Def } \\
\text { 'in the night' }\end{array}$ & $\mathrm{P}$ & \\
\hline $\mathrm{i}$ & Súsúbà & ó & rá \\
\hline & morning & Def & $\mathrm{P}$ \\
\hline & 'in the morning' & & \\
\hline ii & * Susubo & ra & \\
\hline & morning-Def & $\mathrm{P}$ & \\
\hline
\end{tabular}


What has been shown of the definite determiner in (3) appears to defy any uniform phonological account. Particularly unclear is the reason for the nonconvergence of the example in (e, ii) when in fact the expression in (d, ii) is suspected to have obtained from the same process. However, the matter is treated as the product of the grammatical properties of the lexical item súsúbà 'morning' which blocks or prevents it from being base-merged with the definite marker; it can only combine or merge externally with the definite marker to form a constituent, i.e. determiner phrase (DP), as indicated by the grammaticality of the example in (e, i).

The implication of this claim is that, it may not be appropriate to use the orthographic forms of the lexical items as an index to recognise the definite article as a free standing morpheme. In spite of the irregularities contained in the phonological shapes or representations of the definite determiner, I assume that, in all instances, definiteness comes either through a replacement of the final vowel of the noun stem or an addition of either vowel [-o] or [-a] whose distribution can be explained as an effect of the nature of vowel harmony which the language allows. That is to say, the ATR value of the vowel in the noun stem determines the choice of an inflected vowel (affix) that gives the noun its definite reading. What has been said of the definite marker does not spread through all the nouns in Zarma because there are nouns that neither take overt inflections of the type just discussed nor seem to merge overtly with the items already identified as definite markers. For instance, the following nouns do not overtly mark for definiteness or specificity but one piece of semantic evidence is that they are appropriately interpreted at the LF by the interlocutors - i.e. they take default interpretations because the determiner particle is assumed to be covert.

$\begin{array}{lll}\text { 4. } & \text { zààmà } & - \text { knife } \\ \text { ii. } & \text { gùrí } & - \text { egg } \\ \text { iii. } & \text { kòròfó } & - \text { rope } \\ \text { iv. } & \text { làbárì } & - \text { talk } \\ \text { v. } & \text { hángá } & - \text { ear } \\ \text { vi. } & \text { tóndí } & - \text { stone } \\ \text { vii. } & \text { tásà } & - \text { plate } \\ \text { viii. } & \text { ánkóríbé } & - \text { ear ring } \\ \text { ix. } & \text { bíná } & - \text { heart } \\ \text { x. } & \text { rógó } & - \text { cassava } \\ \text { xi. } & \text { fàfà } & - \text { breast } \\ \text { xii. } & \text { kòròkòti } & - \text { maize }\end{array}$


A survey of the examples of nouns without overt definite marker as shown in (4) does not suggest any uniform features which can be said to be responsible for the way they tend to behave. Thus, a potent way of analyzing the situation in the data above which will be consistent with the syntax of Zarma is to propose a phonetically zero definite determiner for those nouns. This proposal is not novel because instances of this abound in the following English words - sheep, information and several others which do not have overt plural markers.

One pertinent question that arises from our analysis is how to account for indefiniteness or unspecificity which lacks morphological marking/representation in Zarma if the zero definite determiner proposal is in the right direction. I start by explaining indefiniteness as an expression or construction in which the listener does not have any knowledge of the referent of the noun in question. The nominal expression kòròfo in each of the sentences in (5) is not ambiguous between two interpretations, i.e., it does not call for either definite or indefinite reading in spite of the absence of indefinite/definite determiner marker on it.

5a. áí dè kòròfó
1sg buy rope Indef
'I bought a rope'
b. áí nà kòròfó dè
$1 \mathrm{sg}$ Perf rope-Def buy
'I have bought/bought the rope'

It is not doubtful; going by the translations of the constructions in (5), that kòròfó 'rope' a bare noun may be interpreted as indefinite or definite without any corresponding change in its morphological form. However, syntactic variation in the order of the object DP is observed. This fact bears directly on a report by Cheng and Sybesma (1999), and Aboh (2004a, 2004b) that Sinitic and most NigerCongo languages do not have definiteness articles of the Indo-European type, but encode definiteness by other syntactic devices that are arguably not expressions of $\mathrm{D}$, i.e., pre- versus post-verbal position. By implication, in addition to the use of overt definite marker, Zarma also encodes definiteness by a syntactic device of pre- versus post-verbal position. Following Jayeola (2016) who treats proper names and pronouns as expressions of $\mathrm{D}$ and also asserts that relative clauses involve a $\mathrm{D}$ that embeds the relative complement clause in Zarma, it is the position of this paper that the examples in (5) involve the category $\mathrm{D}$ which does not have a reflex at Phonetic Form. This account is in tune with Abney (1987), Longobardi (1994), and Cardinaletti and Starke (1999). 
Furthermore, the analysis pursued here suggests that there is no morphological or phonological constraint on the distribution of the definite marker. However, the semantic property of the determiner elements (covert/overt) gives the noun its definite or indefinite reading. Consequently, I treat the indefinite/definite article as an inherent part of the grammar of Zarma which may be realised overtly or covertly on the noun it modifies depending on the specific features of the noun in question. The intuition of Zarma native speakers, guided by convention makes it possible for them to determine or discriminate the choice of $-\mathrm{o},-\mathrm{a}$ and the null/zero variant of the determiner marker.

One advantage of this proposal is that, it is not possible for personal pronouns and the definite article to co-occur, predicting that they are in complementary distribution. This explains the ungrammaticality of the following constructions.

$$
\begin{array}{lll}
\text { 6a. } & \text { *írì } & \text { kùsó } \\
& 1 \mathrm{pl} & \text { water pot-Def } \\
\text { b. } & * \text { áí } & \text { sánáá } \\
& 1 \mathrm{sg} & \text { needle-Def }
\end{array}
$$

The definite article inflection on the nouns is the cause of the non-convergent expressions in $(6 a \& b)$; this is why the absence of such an inflection in $(6 c \& d)$ makes the expressions to conform.

6c. írì kùsú
$1 \mathrm{pl}$ water pot
'our water pot'
d. ái sáná

1 sg needle
'my needle'

It is apparent from the illustrations in (6) that pronoun and determiner occupy the same structural position. Perhaps, it is also safe to say that determiner in Zarma is not considered as a nominal adjunct although it modifies nouns but does not cooccur with pronoun. This clearly indicates that determiner is essentially the element that projects and its property gives the resultant phrase its definite or indefinite reading. Thus, it is a functional category. 


\section{Analysing the Basic Determiner Phrase}

The DP-hypothesis postulated by Abney (1987) as well as the LCA considers nominal category in the DP as a complement of D, however, the examples in (7) below suggest that the complement of D in Zarma occurs to its left contra LCA. This situation is not odd; it only shows language specific idiosyncrasies. Based on this fact, I recognise the variation in the linear order as the effect of movement.
7a. kùsó
water pot -Def
'the water pot'
b. hábó
market-Def
'the market'
c. mà ó
name Def
'the name'
d. sáná á
needle Def
'the needle'

The bare forms of the nouns in (7a,b) are kùsú 'water pot' and hábu' 'market' respectively. Thus, it is speculated that the definite marker $o$ is base-merged with the nouns causing their pronunciations to be affected. On the other hand, examples (7c, d) show that definiteness externally merges with the noun to project into DP.

Following from the aforementioned divisions, first, I consider the surface order of constituents within the basic DP in Zarma using examples (7c, d) as a movement of NP to the Spec DP because definiteness is realised as a free standing morpheme that externally merges with the noun. The analysis is presented in (8a) below using example (7d). 
$8 \mathrm{a}$.

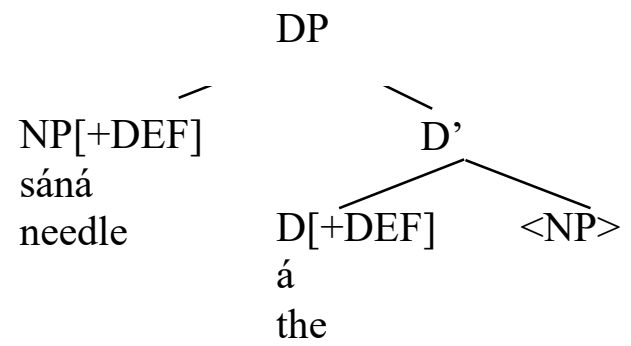

The configuration in (8a) shows that the NP sána' 'needle' starts as the complement of the head $\mathrm{D} \dot{a}$ 'the', but has to raise to a higher position than $\mathrm{D}$ to check its definite features in overt syntax.

The second manner of definiteness marking described by the data in $(7 \mathrm{a}, \mathrm{b})$ shows that the particle - $O$ 'the' is not suffixed to the noun kùsú 'water pot' and hábú 'market' but seems to get fused (i.e. base-merged) with the nouns. This assumption relies on the fine-grained idea conceived within the minimalist syntax which posits that bound morphemes (i.e. inflectional and derivational) are combined by merge. This is in line with the Inclusiveness Condition (IC) which states that a Logical Form object must be built from the features of the lexical items of the corresponding initial numeration. It means that kùso' 'the water pot' for instance enters the derivation fully inflected and carries a triple set of features: semantic, syntactic and phonological features. This being the case, kùsó, for instance. has information about definiteness based on its semantic feature as well as its phonological feature which is not identical with kùsu' 'water pot' and the likes. Following from the theoretical explanations, I propose that $\mathrm{N}$ would covertly raise to $\mathrm{D}$ as in (8b) using example (7a). The justification for our proposal comes from semantic evidence and the fact of morphology in syntax.

$8 b$.

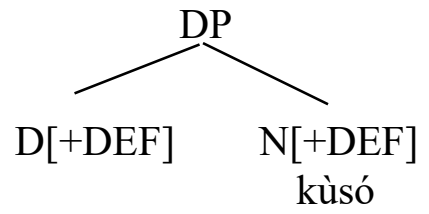

The analysis in (8b) describes how the syntactic component interacts with the Phonetic Form (PF) aspect of Zarma grammar. In summary, the descriptions 
given have protected the position of the LCA which disallows right adjunction and assumes a head-complement as the universal order.

\section{Noun-Attributive Modifiers}

Traditionally, adjectives and relative clauses are modifiers of nouns. As mentioned in the previous section, relative clauses involve a $\mathrm{D}$ that embeds the relative complement clause. Hornstein et al. (2005) describe relative clause as a sentence that can function as a kind of giant adjective. This is shown in the examples below.

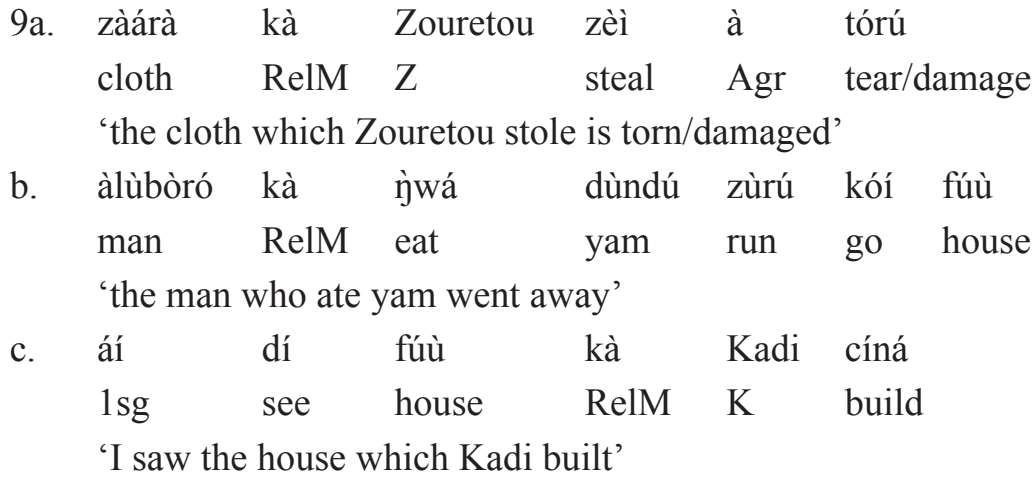

It is clear from (9) that relative clauses are post nominal qualifiers in Zarma. However, it is not the focus of this paper to go further on the properties or structural build-up of relative clauses since the interest of this article is on the internal structures of adjectives and how they relate to the nouns they modify vis-à-vis the marking of definiteness. Consequently, the section that follows is devoted to the discussion of adjectives in Zarma.

\section{Zarma Adjectives}

One attributive modifier in Zarma is the adjective which in nominal expressions modifies the noun and describes some property of the thing referred to by the noun. Morphologically, adjective qualifiers in Zarma are all consonant initial and mostly consist of two syllables which have CVCV structure without any known derivational process. This is unlike Gungbe, Aboh (2004a), Turkish and Persian, Ghaniabadi et al. (2006), Chinese, Yang (2007), Yoruba, Ilori (2010), among others, where attributive adjectives are said to be derived. This category of modifiers has attributive characteristics that can be grouped into shape, colour, height, dimension etc. Attributive adjectives in Zarma essentially occur post nominally; a change of this order results in ill-formed or non-converging expressions. This is shown in (10). 
Jayeola, W.A./Legon Journal of the Humanities Vol. 30.2 (2019)

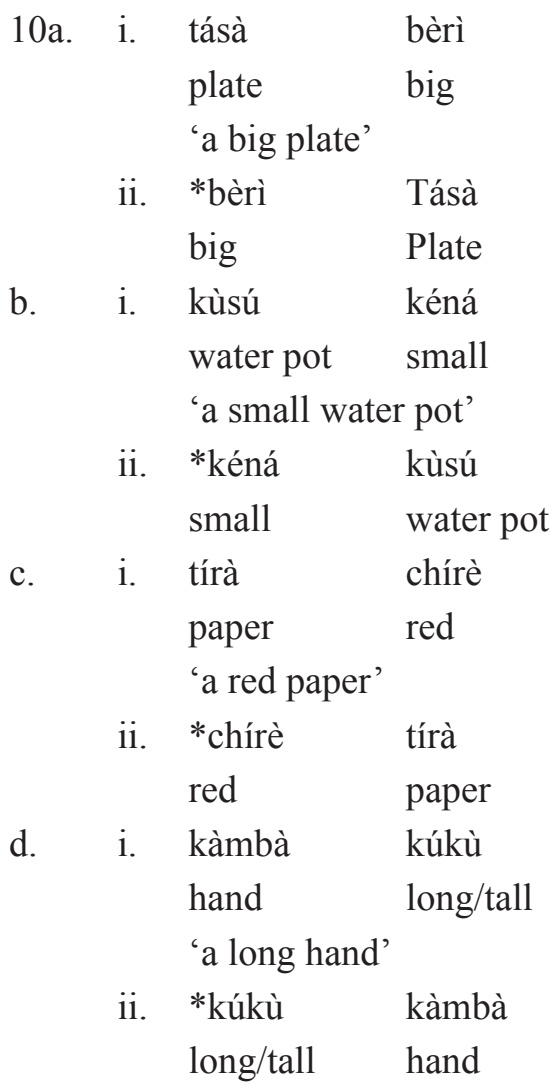

It is plausible to predict from the glosses of the data in (10) that indefiniteness as I earlier mentioned is not morphologically marked, although it is assumed to be present at the LF. Consequently, the merger of noun and adjective, using the examples in (10) is treated as a projection of two major categories which is headed by a null-D; reminiscent of what I said of indefinite article in the previous section. However, it is the position of this paper; as it will be argued later, the adjective, a class of modifier, is an adjunct because it can serve as a modifier of plural nouns. This is shown in the following examples.

11a. fàfà-àí bèrì
breast-P1 big
'big breasts'
b. tásà-àí Kéná
plate-P1 small
'small plates'


What is observed of the adjectives in (11) is not the same with categories such as quantifiers and numerals which Jayeola (2016) treats as functional items. As opposed to the situation in (11), quantifiers and numerals do not co-occur with plural morphemes within a DP. In another vein, numerals and quantifiers do not inflect whereas adjectives do. This phenomenon as it applies to Zarma will be shown in the discussions below.

A striking and intriguing scenario is created when the post nominal enclitic definite article occurs alongside the adjective within a DP. The gap between the noun and the adjective is widened because the determiner intervenes between the noun and the adjective. In this case, the head of the DP, enclitic D or a free standing $\mathrm{D}$, assumed to occur phrase initially allows the raising of $\mathrm{N}$, its complement, for phonological support. Consider the examples in (12).

12a. má ó bèrì

name Def big

'the big name'

b. tírà á bèrì

paper Def big

'the big paper'

c. wúndó téjí

house-Def new

'the new house'

I take the above examples (12a-c) as a projection of $\mathrm{D}$ because the definite article markers found in them actually account for the definite reading which the expressions carry. If for instance the free standing definite morpheme in (12b) or its suffixed variant in (12c) is removed, the resultant expressions will have an indefinite reading as shown in (13a and b) respectively.

13a. tírà bèrì

paper big

'a big paper'

b. wúndí téjí

house new

'a new house'

Noun-adjective constructions in Zarma still provide some other puzzling fact. The adjective presents a phenomenon where a suffixed determiner or determinerlike particle appears on it, translating to the possibility of adjective inflecting for 
determiner. From this fact, it appears that Zarma attests to what has been described in the literature as determiner doubling. In this case, there is the double occurrence of either a free standing or suffixed determiner element which has superficially the same content. The uninflected form for bèrò is bèrì, it is yéná for yéyí and téjo for téjí. This is demonstrated in (14).

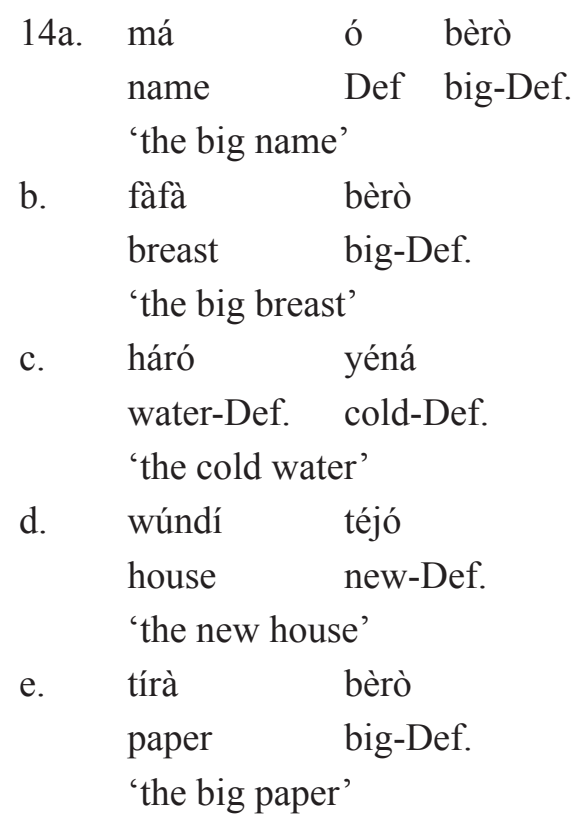

A clear comparison of the examples in (12a-c) with the ones in (14b, d \& e) presents a better understanding of the phenomenon of double definiteness. In those examples, only the adjectives inflect for definiteness making the appearance of the suffixed/enclitic definite article on the nouns optional. I do not regard this as an instance of agreement but a projection of another determiner phrase because the situation is not a case of an element taking on the morphosyntactic properties of another element. The omission of the two suffixed/enclitic determiners would give the expression an indefinite reading similar to the one earlier shown in (10 \&12). Consequently, whenever a concrete reading is intended, one of the two enclitic definite articles is obligatory.

Contrary to what I have said of the definite article, it is difficult to claim the existence of indefinite determiner doubling because it is not morphologically marked, this is unlike some Germanic varieties, Wood (2012), Northern Swedish, Delsing (1993). It is reasonable to mention that, in Zarma, the presence of double determiner does not license a change or reversal in the canonical order of Noun 
Determiner Adjective Determiner (NDAD). It is this condition that explains why the following expressions do not converge at spell-out.

15a. *bèrò kùsó

big-Def water pot-Def

b. *yéná háró

cold-Def water-Def

What is indicated in (15) is quite different from the situation in Greek, (Alexiadou, 2006, and Alexiadou \& Wilder, 1998), where both post-nominal and pre-nominal positions are possible; in the absence of Determiner spreading however, the order of constituents in its noun phrases is fixed or rigid. ${ }^{1}$

According to Aboh (p.c.), what is being taken as a case of determiner doubling in Zarma may be considered or viewed as an instance of plural agreement found in French. However, it is not the conviction of this study that the behaviours of the two (determiner doubling and plural agreement) bear some sense of resemblance with each other. A close look at the two instances predicts some degree of variations: in French, determiner, adjective and noun agree in terms of number as indicated at the footnote whereas Zarma does not display noun-adjective agreement both in terms of number as well as definite article indication. Therefore, it may not be plausible to see the two instances as products of an identical process ${ }^{2}$. One plausible approach to the treatment of $\mathrm{N}$-article and Adjective-article expressions in Zarma is to analyse the enclitic article on the noun as nominal agreement marker or the spell-out of an agreement relation between a noun and its specifier in AgrP. However, analysing the inflection of noun and adjective as agreement relations will be an inconsistent representation of Zarma syntax, because it is understood from the discussion so far that Endocentric Concordial Pattern (Stockwell, 1977, p. 9) does not exist between nouns and their modifiers. Similarly, agreement of this nature does not also occur even in the IP-clause. Consider the examples below.

\footnotetext{
${ }^{1}$ See Alexiadou and Wilder (1998: 1) for the detailed discussion of how determiner spreading can relax the order of elements rigid or flexible.

${ }^{2}$ The following examples represent the fact of plural spreading in French:

a. Le grand garçon- 'the big boy'

b. les grands garçons- 'the big boys'

c. La belle maison- 'the fine house'

d. les belles maisons- 'the fine houses'
} 
Jayeola, W.A./Legon Journal of the Humanities Vol. 30.2 (2019)

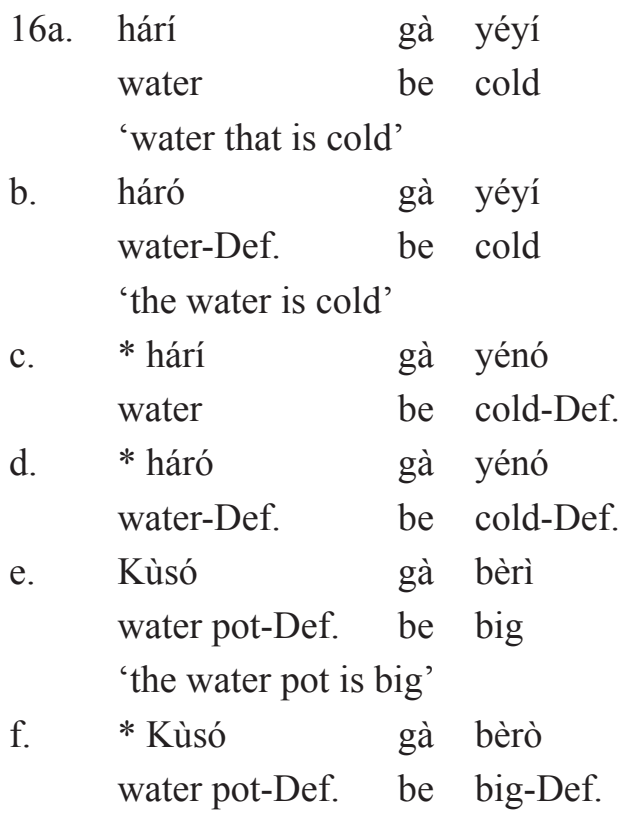

A close study of the examples in (14) and (16) shows that the two types of AP-modifier in Zarma viz: attributive (DP-internal modifier) and predicative (DPexternal AP) are all generated to the right of the N, thus no divide is made between pre- and post-nominal APs. One other feature of adjectives conceivable from the glosses in (16) is that zero copula for predicate adjectives may not be possible.

A plausible claim/proposal which I contemplate about the crashed expressions in (16) is that agreement is not allowed in predicative constructs. It seems that the auxiliary element (copula) gà 'be' blocks what could have been considered as the morpho-syntactic agreement relation between the modified noun and its modifier AP. This analysis predicts that the enclitic definite determiner on adjective is not a trait of agreement, if it were to be, the expressions ought to have converged. In conclusion, I recognise the situation as a case of double definiteness where the post-nominal definite determiner projects and heads the DP such that there is a second lower determiner projection that hosts the article-enclitic/ suffixed to the adjective. The derivation of this structure is analysed in the following section.

\section{Adjectival Modification and Determiner Doubling in Zarma}

What has been shown as regards adjectives and nouns inflecting for definite article in Zarma is not the same with what has been reported in the literature for many Niger-Congo languages, especially the Bantu sub-family which display noun- 
adjective agreement in terms of number. Thus, it may be out of place to consider the situation in Zarma as a case of definiteness agreement because empiricism does not show that the definite article should agree in its + definite feature (specification) since either of the noun or the adjective can be bare and the expression still clearly and unambiguously interprets as definite. Consider the following examples.

17a. kùsú bèrò
water pot big-Def
'the big water pot'
b. kùsó bèrì
water pot-Def big
'the big water pot'
tíràa bèrì
paper-Def big
'the big paper'
hárí yéná
water cold-Def
'the cold water'
háró yéyí
water-Def cold
'the cold water'

From the data in (17), there appears to be no clue as to whether the uninflected/ bare nouns/ adjectives have [ + definite] specification or not because indefiniteness as earlier mentioned is not morphologically marked in Zarma. Invariably, the situation does not seem to be as clear as it is in Modern Greek, (cf. Alexiadou \& Wilder, 1998; Simpson, 2001). The examples from Greek as presented by Simpson (2001, p. 130) illustrate the distinction and this is shown in (18).

18a. to meghalo to Ghermaniko to piano
the big the German the piano
'the big German piano'
b. *ena meghalo to Piano
a big the Piano

The phenomenon in (18) can be marked as an instance of definiteness agreement. This is because a noun with a definite determiner should always select 
an adjective with a definite determiner also. This explains the reason for the illformedness of (18b). The situation here is largely different from the one found in Zarma.

Of interest to the analysis pursued here is the fact that adjectival modification appears to tolerate a greater measure of freedom in the ordering of multiple modifier strings. This is strictly in line with Hawkin's (1983) prediction. Consider the following examples.

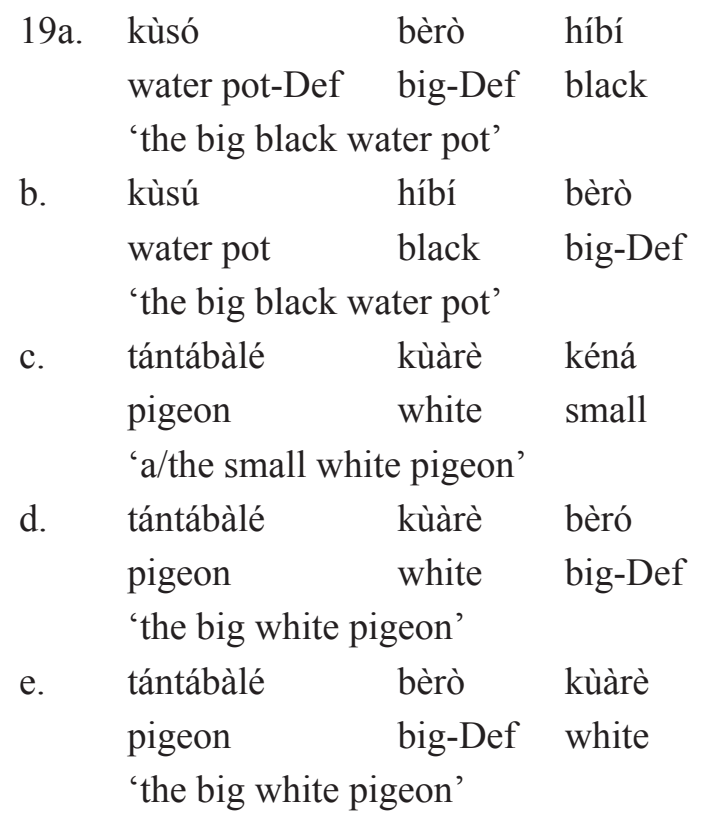

The expressions in (19) have not helped to show whether each adjectival modification can be recognised as an instance of adj-DEF modification because definiteness is not considered as being marked on some of them, at least overtly. However, in the spirit of Simpson (2001), I would like to postulate that definiteness or indefiniteness as the case may be, is present but not overt on some of the adjectives which probably explains why a greater degree of freedom in ordering is tolerated. This is similar to the situation in Mandarin reported by Simpson (2001, p. 150) and Greek, reported by Alexiadou and Wilder (1998, p. 325). These studies serve as a veritable support for adjectival modification as DP-hypothesis and a good guide to establish determiner doubling as a phenomenon in Zarma.

Interestingly, it is obvious that attributive adjectives entirely follow 
Jayeola, W.A./Definiteness in the Zarma determiner phrase

the modified DP and the adjectives optionally inflect for definiteness whereas indefiniteness is not marked overtly at all. Since I have not been able to establish the existence of noun-adjective agreement nor assume definite article spreading in Zarma, it is reasonable to consider determiner doubling (definite) as a thriving phenomenon in the language.

\section{An Analysis of Double Definiteness}

Following from the foregoing assumption, two possible approaches to the analysis of adjectival modification are available: they can be analysed as a category of adjunct or as a functional head.

The surface order of double definiteness is better analysed using the adjunction approach because adjectives in this kind of projection cannot be considered as functional heads, rather I assume an invocation of the LCA which makes it possible for the adjective to left adjoin to the lower D. The assumption in this regard is that the post nominal article projects and heads the DP where NP raises to $\mathrm{D}$ and that there is a second lower determiner projection that hosts the definite article enclitic to the adjective where the adjective is assumed to originate at the complement position of the lower D. This phenomenon presents an instance of DP recursion where the upper DP dominates the lower DP (cf. Collins, 2016, pp. 14-15). In another vein, the structure shows that the particle - $O$ ' the' is not suffixed to the adjective bèrì 'big'; it rather gets fused (i.e. base-merged) with the adjective. Similar to an earlier proposal, bero 'the big' enters the derivation fully inflected and carries a triple set of features: semantic, syntactic and phonological features. As suggested by the analysis in (20), the head ADJ must be marked with definiteness when $\mathrm{D}$ is definite and that a definite $\mathrm{D}$ must have a host. It means that ADJ covertly raises to $\mathrm{D}$.

20.

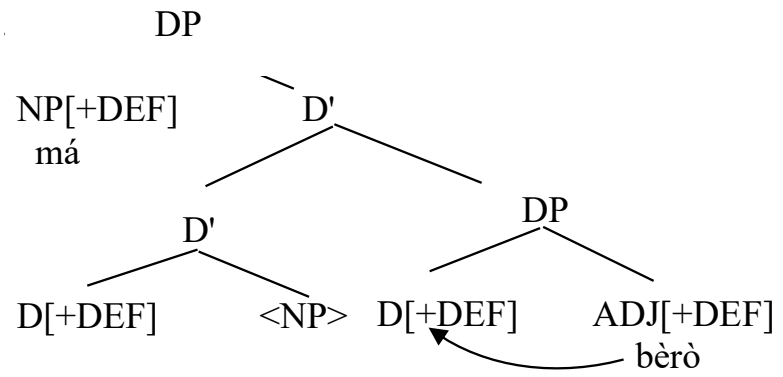


The analysis provided in this regard does not involve a merger (internal/ external) of redundant elements; it rather makes it possible for every symbol of grammar to be interpreted. This is in strict compliance with the Principle of Full Interpretation. The compatibility of this analysis or assumption depends largely on: (a) the noun and its enclitic/suffixed article occupy the DP initial position, while (b) the adjectives follow the noun or occur in post-nominal position. The order in Zarma contrasts with the fact of Swedish where the adjectives occur pre-nominally and the adjectival article occupies the DP-initial position as shown in (21).

21 det store huset
the big house-the
'the big
house'

(Bernstein, 2001, p.549).

The situation in Zarma is not the exact mirror image of what obtains in the Swedish example. However, as previously emphasised, the proposal for a lower determiner is in line with the prediction of the LCA, Kayne (1994) as well as the position held by Delsing (1988, 1993), Santelmann (1993), among others. The non-marking of definiteness on some nouns and/or adjectives notwithstanding, the analysis is not affected; this study is guided by the assumption that a null functional head for either of the higher or lower determiner projections or both exist as definiteness may be encoded by other devices other than morphological as earlier explained.

Finally, it is pertinent to mention that double definiteness account cannot be extended to constructions in which either of numeral, demonstrative or quantifier occurs with adjective to modify nouns. This situation accords with the Split-DHypothesis assumed in Aboh (2004a, 2004b, 2013). In line with this proposal, Giusti $(2015$, p. 70) asserts that the split DP provides an escape hatch for any kind of element, either AP (Adjective Phrase) or genitive DP. Thus, this present study contemplates a different account for the treatment of this type of construction which I take up in the following sub-section.

\section{Numeral/Demonstrative/Quantifier + Adjectival Modification}

The decision to provide a different account for constructions in which adjectives and numerals/demonstratives/quantifiers occur is premised on the following reasons: (a) the proposal that each of the definite determiner, numeral, demonstrative and quantifier is a functional projection and also in complementary distribution, (b) numerals, demonstratives and quantifiers are all free standing 
morphemes and not inflectional as definite determiner often tends to be. Given the above reasons, a different account is desirable in terms of how the expressions are derived as well as how they interact.

The occurrence of an adjective between the noun and numeral/ demonstrative/ quantifier at surface structure as well as the absence of the enclitic definite determiner on the noun and the adjective as shown in the asterisked examples in (22) further confirms the claim earlier made that definite article and its subsets numeral, demonstrative, quantifier do not overlap. In the light of this assertion, a different analysis is required to account for the surface linear order.

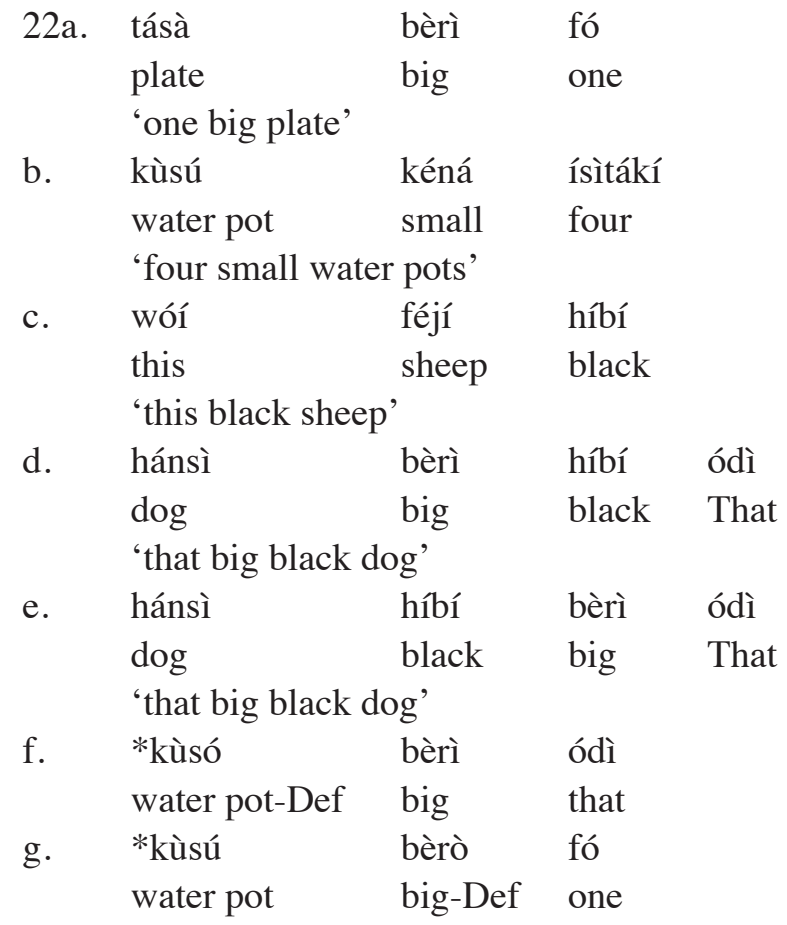

As I have earlier explained, examples (22f \& g) in the above expressions crash because there are competitions among the different subsets of determiner elements (i.e. definite determiner and numeral) that occur within the same phrase (functional projection).

To treat the adjective as an adjunct to the noun in line with the LCA, which predicts that the adjective is left adjoined to the noun and that the entire NP moves to Spec of NumrlP/DemP as the case may be, will not yield the correct linear order which Zarma exhibits. This is exemplified in (23b) using example (23a). 
Jayeola, W.A./Legon Journal of the Humanities Vol. 30.2 (2019)

23a. tásà bèrì fó/ódì
plate big one/that
'one/
that
big
plate'

b.

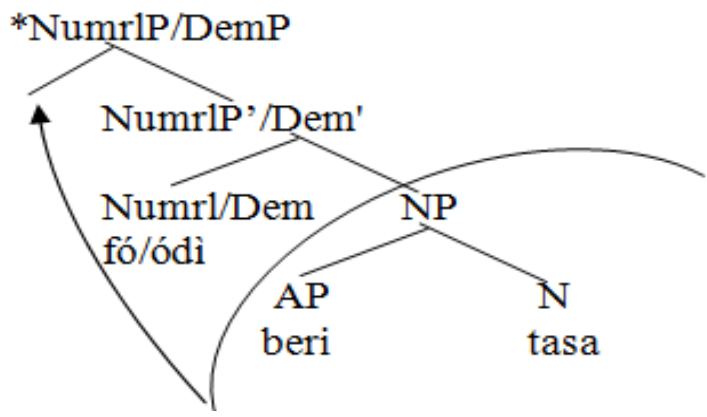

The structure in (23b) presents [Adjective-Noun-Numeral/Demonstrative] order contrary to the [Noun-Adjective-Numeral/Demonstrative] which Zarma tolerates. It therefore seems that the manner of adjunct approach which the LCA assumes is inappropriate. Another possible approach in this direction would be to treat adjectives like other modifiers which form a closed class in some languages as functional projections that introduce a DP complement. This approach has been adopted in works like Aboh (1999, 2004a); Cinque (2005); Ajiboye (2007) among others. In the spirit of their analyses, the DP first moves to Spec ModP and the ModP raises to Spec DemP; an approach that translates to what Aboh (1999, 2004a) regards as 'Snowball/Roll-up' movement. Snowballing, which allows pied-piping of a maximal projection continues until it reaches the Spec of the highest phrase because it depends on the number of intervening functional heads.

Unfortunately, the snowball/roll-up approach fails to account for the peculiarity observed in the Zarma data; several intervening functional projections are not tolerated within its D-system, which is the reason for the adoption of the roll-up/snowball approach. In the sense of the fact of Zarma data, the functional approach does not seem to serve any useful purpose; therefore, I contemplate a revisit of the adjunct-based approach proposed by Dechaine (1993).

I start the defence of this choice by mentioning that the reading provided by Numeral/Demonstrative plus adjective modification is not tied to or dependent on the adjective and so, it is not justifiable to treat adjectival modification as a 
functional head, similar to and in the spirit of the treatment of double definiteness. Instead of the functional approach, I shall in the spirit of Dechaine (1993), treat adjectives in this construction as a based-generated adjunct where the surface linear order is derived through the movement or raising of the entire NP to the Spec of NumrlP/DemP as the case may be. This is structurally represented in (24).

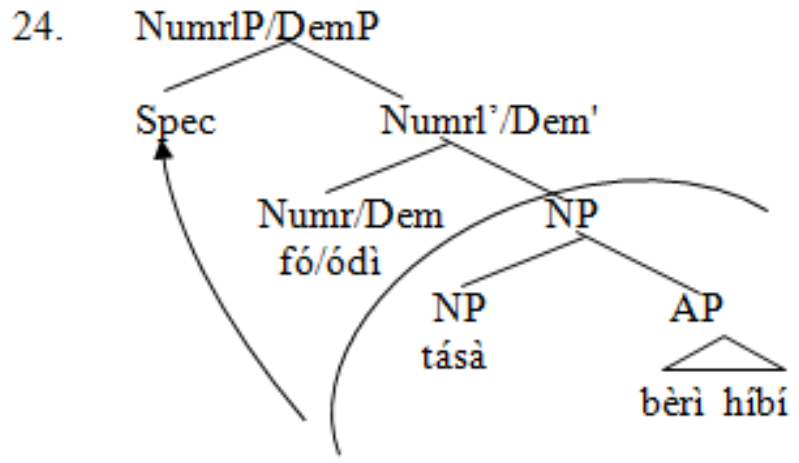

The resolve to retain the base-generated adjunct analysis is informed first, by its simplicity, a requirement that the data of Zarma also satisfies. In this regard, no movement of the assumed NP complement to Spec-AP is required to have the noun-adjective order which the language attests. It therefore does not seem to serve any useful purpose to appeal to what Chomsky (1995) refers to as Generalized Pied-Piping or Snowballing movement (Aboh, 2004a). Another justification for the refined analysis is linked to language internal evidence. Unlike what the roll-up/ snowball approach assumes, this paper does not deem it fit to stipulate a specific modifier sequence in Zarma. Considering the examples in (22), it is apparent that adjectives of different types; dimension and colour, for instance do not require any specific sequence of order. This is not the case with Gungbe, Aboh $(1999,2004 a)$ and Buli, Sulemana (2012).

Finally, it is not possible to analyse the situation under consideration in Zarma as a case or an instance of syntactic movement of the AP in the surface linear order. Besides, adopting the functional approach will be inconsistent with the account which has been given of the double definiteness and at the same time, it will indeed be unnatural.

\section{Conclusion}

The attempt in this paper has been to explain that definite article in Zarma is realised sometimes as an enclitic item on the noun and at other times as a freestanding item. Zarma definite articles may also be realised as a covert or a null 
category. However, it is taken as the element that heads the projection in each case where the noun originates as its complement. The data used in this study show that definite determiner marker can also be base-merged with post nominal adjectives. The post-nominal position of the head of the DP on the one hand is understood as a product of phonological support or order of merge. On the other hand, the strong specifier feature of the head D' must be checked before spell-out for the derivation to converge. On the basis of syntactic form and semantic interpretation, the study shows that Zarma definite determiners can occur with either nouns or adjectives or both. This means that adjectives in definite DPs make possible an additional (suffixed/base-merged) lexical determiner. In all of these cases, no different readings obtain. Similarly, it is understood that the definite determiner and its subsets numeral, demonstrative, and quantifier do not overlap. I consider the discussion of determiner doubling constructions in this paper as a great contribution to the ongoing debates on the syntax and semantics of the definite determiner and its subsets and how they interact which will likely translate into a technical proposal. 


\section{References}

Abney, S. P. (1987). The English noun phrase in its sentential aspect. (Doctoral thesis). MIT. Distributed by MITWPL.

Aboh, E. O. (1999). From the syntax of Gungbe to the grammar of Gbe. (Doctoral thesis). University of Geneva.

Aboh, E. O. (2004a). The morphosyntax of complement-head sequences: Clause structure and word order patterns in Kwa. New York: Oxford University Press.

Aboh, E.O. (2004b). Topic and focus within D. In L. Cornips, \& J. Doetjes (Eds.), Linguistics in the Netherlands, 21, 1-12. Amsterdam: Benjamins.

Aboh, E. O. (2013). The morphosyntax of the nominal left periphery. Handout, African Linguistics School III, Nigeria, July, 2013.

Ajiboye, O. (2007). The syntax and semantics of Yoruba nominal expressions. The Linguistic Association of Nigeria in collaboration with M \& J Grand Orbit Communications Limited, Port Harcourt, Nigeria.

Alexiadou, A. (2006). On the cross-linguistic distribution of (in)definiteness spreading. ÖLT syntax workshop, Universität Klagenfort.

Alexiadou, A. \& Wilder, C. (1998). Adjectival modification and multiple determiners. In A. Alexiadou, \& C. Wilder (Eds.), Possessors, predicates and movement in the DP. (pp. 303-332). Amsterdam: John Benjamins.

Bernstein, J. B. (2001). The DP hypothesis: identifying clausal properties in the nominal domain. In M. Baltin, \& C. Collins (Eds.), The handbook of contemporary syntactic theory. (pp.536-561). Malden, MA: Blackwell Publishers.

Cardinaletti, A. \& Starke, M. (1999). The typology of structural deficiency: A case study of the three classes of pronouns. In H. V. Riemsdijk (Ed.), Clitics in the languages of Europe. (pp. 145-233). EUROTYP 20-5, Mouton de Gruyter, Berlin - New York.

Cheng, L. L, \& Sybesma, R. (1999). Bare and Not-So-Bare nouns and the structure of NP. Linguistic Inquiry, 30, 509-542.

Chomsky, N. (1993). A minimalist program for linguistic theory. In K. Hale, \& S. J. Keyser (Eds.), The View from Building 20: Essays in Linguistics in Honour of Sylvain Bromberger. (pp. 1-52). Cambridge, MA: MIT Press.

Chomsky, N. (1995). The minimalist program. MIT. Cambridge, Mass.

Cinque, G. (2005). Deriving Greenberg's universal 20 and its exceptions. Linguistic Inquiry, 36 (2), 315-332.

Collins, C. (2016). Introduction to minimalist syntax. The African Linguistics School Lectures. Cote-d'Ivoire, July, 2016. 
Jayeola, W.A./Legon Journal of the Humanities Vol. 30.2 (2019)

Dechaine, R-M. (1993). Predicates across categories: towards a category-neutral syntax. (Doctoral thesis). UMass Amherst.

Delsing, L. O. (1988). The Scandinavian noun phrase. Working Papers in Scandinavian Syntax 42, 52-79.

Delsing, L. O. (1993). The internal structure of noun phrases in the Scandinavian languages. (Doctoral thesis). University of Lund.

FassiFehri, A. (1999). Arabic modifying adjectives and DP structures. Studia Linguistica 53, 105-154.

Ghaniabadi, S., Ghomeshi, S. \& Sadat-Tehrain, N. (2006). Reduplication in Persian: A morphological doubling approach. Proceedings of the 2006 Annual Conference of the Canadian Linguistic Association.

Giusti, G. (2015). Nominal syntax at the interfaces: A comparative analysis of languages with articles. Cambridge Scholars Publishing.

Hawkins, J. (1983). Word order universals. New York, Academic Press.

Ilori, J. F. (2010). Nominal constructions in Igala and Yoruba. (Doctoral thesis). Adekunle Ajasin University, AkungbaAkoko. Ondo State, Nigeria.

Jayeola, W. A. (2016). A movement approach to word order variations in Zarma, a Nilo-Saharan language. (Doctoral thesis). University of Ibadan, Ibadan, Nigeria.

Kayne, R. S. (1994). The antisymmetry of syntax. Cambridge, Mass. MIT Press.

Longobardi, G. (1994). Reference and proper names: A theory of N-movement in syntax and logical form. Linguistic Inquiry, 25 (4), 609-665.

Matthewson, L. (1998). Determiner systems and quantificational strategies: Evidence from Salish. Holland Academic Graphics, The Hague.

Santelmann, L. (1993). The distribution of double determiners in Swedish: Den support in Do. Studia Linguistica, 47, 154-176.

Simpson, A. (2001). Definiteness, agreement and the Chinese DP. Language and Linguistics, 2 (1), 125-156.

Stockwell, R. P. (1977). Foundations of syntactic theories. New Jersey: Englewood Cliffs Inc.

Sulemana, A-R. (2012). The structure of the determiner phrase in Buli. (M. PHIL. Dissertation). University of Ghana, Legon.

Wood, J. (2012). Indefinite determiner doubling. Clauses/nominals workshop. University of Aarhus, December 14, 2012.

Yang, G. (2007). Reduplication, atelicity and pluractionality. Paper presented at the City University of Hong Kong, August 2007. 